\title{
Sequential C-F bond functionalizations of trifluoroacetamides and acetates via spin-center shifts
}

\author{
You-Jie Yu'*, Feng-Lian Zhang', Tian-Yu Peng', Chang-Ling Wang1, Jie Cheng', Chen Chen', \\ Kendall N. Houk ${ }^{2}+$, Yi-Feng Wangi,3,4 \\ ${ }^{1}$ Hefei National Laboratory for Physical Sciences at the Microscale, Department of Chemistry, University of Science and Technology of China, 96 Jinzhai Road, Hefei, Anhui \\ 230026, China. 'Department of Chemistry and Biochemistry, University of California, Los Angeles, CA 90095, USA. ${ }^{2}$ Center for Excellence in Molecular Synthesis of CAS, \\ Hefei, Anhui 230026, China. ${ }^{4}$ State Key Laboratory of Elemento-Organic Chemistry, Nankai University, Tianjin 300071, China.
}

*Theses authors contributed equally to this work.

†Corresponding author. Email: houk@chem.ucla.edu (K.N.H.); yfwangzj@ustc.edu.cn (Y.-F.W.)

Defluorinative functionalization of readily accessible trifluoromethyl groups constitutes an economical route to partially fluorinated molecules. However, controllable replacement of one or two fluorine atoms while maintaining high chemoselectivity remains a formidable challenge. Here we describe a general strategy for sequential $\mathrm{C}-\mathrm{F}$ bond functionalizations of trifluoroacetamides and trifluoroacetates. The reaction begins with activation of a carbonyl oxygen atom by a 4-dimethylaminopyridine-boryl radical, followed by a spin-center shift to trigger the $\mathrm{C}-\mathrm{F}$ bond scission. A chemoselectivity-controllable two-stage process enables sequential generation of difluoro- and monofluoroalkyl radicals, which are selectively functionalized with different radical traps to afford diverse fluorinated products. The reaction mechanism and the origin of chemoselectivity were established by experimental and computational approaches.

Mono- and difluoroalkyl-substituted organic molecules have valuable applications as pharmaceuticals ( 1,2$)$, agrochemicals (3), and materials (4) owing to the unique physical and biological properties of fluorine atoms $(5,6)$. The synthesis of these target molecules has thus been of longstanding interest. Over the past decades, many mono- and difluoroalkylating precursors as well as fluorination reagents and strategies have shown robust applications (7-16). C-F bond functionalization of readily accessible trifluoromethyl groups has also proved an effective pathway, in particular for the synthesis of challenging, or otherwise unattainable products (17-29). However, successively replacing two fluorine atoms with various functionalities while maintaining high chemoselectivity is exceedingly challenging $(30,31)$ because the C-F bond strength continuously decreases as defluorination proceeds (5), often resulting in exhaustive defluorination (17, 19, 32, 33). Developing strategies to address this issue would provide a particularly economical and valuable route to di- and monofluorinated products from inexpensive $\mathrm{CF}_{3}$ sources.

Functionalization of $\mathrm{CF}_{3}$ groups generally proceeds through heterolytic cleavage of a $\mathrm{C}-\mathrm{F}$ bond, affording difluoro-substituted carbocation or carbanion intermediates (Fig. 1A, top left) (17-22). In contrast, transformations via fluoroalkyl radical intermediates, which can provide different reaction pathways for chemical bond formation, are understudied, due to the high bond dissociation energy (BDE) of the $\mathrm{C}-\mathrm{F}$ bond constraining homolytic cleavage (5).
Recently, the groups of König (34), Jui $(35,36)$, Bandar (37), and Gouverneur (38) disclosed an intriguing strategy to generate aryldifluoromethyl radicals from $\mathrm{CF}_{3}$-substituted arenes, wherein arene radical anions generated via singleelectron reduction serve as intermediates and a fluoride anion is eliminated (Fig. 1A, top right). However, a general method applicable to readily accessible trifluoroacetic acid derivatives and capable of selectively forming diand monofluoroalkyl radicals (Fig. 1A, bottom), has not been developed.

In seeking a solution to achieve the aforementioned transformations, we were drawn to a spin-center shift (SCS)based radical process, which involves 1,2-radical delocalization and leaving group elimination (39). This process has been observed and studied in various biological applications $(40,41)$. For example, during DNA biosynthesis, the SCS pathway catalyzed by ribonucleotide reductase class (I-III) is known to be a key step in the formation of deoxyribonucleoside diphosphates (Fig. 1B, top) (42). The mechanism involves a $\beta-\mathrm{C}-\mathrm{O}$ bond scission of radical Int-I, forming a new carbon-centered radical with the elimination of water as a coproduct. There have also been reports on SCS in organic synthesis, using chloride, bromide, and hydroxyl groups or their activators as the $\beta$-leaving group (Fig. 1B, bottom) (43-48). Recently, MacMillan reported robust alkylation approaches mimicking this SCS process with the use of alcohols as alkylating agents $(49,50)$. More recently, Melchiorre (51), Wang (52), and Rovis (53) also described 
elegant SCS-involved alkylation reactions. Despite these advances, the SCS-promoted C-F bond cleavage remains an unanswered challenge in organic synthesis (54). Such a transformation could offer a mechanistically distinct strategy for defluorinative functionalization of $\mathrm{CF}_{3}$ groups. Were a stepwise SCS to proceed in a controllable manner, an approach to enable sequential $\mathrm{C}-\mathrm{F}$ bonds replacement would be achievable.

With this in mind, we posited a discrete two-stage process with each stage involving an SCS for the C-F bond cleavage of trifluoroacetic acid derivatives (Fig. 1C). In stage $\mathbf{A}$, the first SCS of the transient Int-II generated through the attack of the carbonyl oxygen atom by a radical promotor occurs, resulting in cleavage of a single $\beta-\mathrm{C}-\mathrm{F}$ bond. The resulting $\alpha, \alpha$-difluorocarbonyl radical, Int-III, can be subsequently captured by a radical trap to provide an $\alpha, \alpha$-difluoroacetyl product and complete the monodefluorinative transformation. In stage $\mathbf{B}$, if the radical promotor is continuously present, the stage A product participates in a second SCS to generate the radical Int-V, which is then trapped by a second component to furnish monofluorinated products. The use of different traps in stages $\mathbf{A}$ and $\mathbf{B}$ should enable rapid and efficient synthesis of densely functionalized monofluoro products. The challenge is how to make the two-stage sequence controllable meanwhile circumventing exhaustive defluorination.

\section{Controllable mono- and dihydrodefluorination reactions}

To verify the feasibility of the proposed two-stage process, we began by investigating the controllable mono- and dihydrodefluorination reactions of trifluoroacetamides and trifluoroacetates, where one or two C-F bonds are selectively reduced. Based on recent findings, certain Lewis base-boryl radicals $(55-58)$ are nucleophilic $(59,60)$ and can attack carbonyl oxygen sites (61); our initial studies focused on the application of these radicals as promotor. We found that 4-dimethylaminopyridine (DMAP)- $\mathrm{BH}_{2} \bullet$, which is generated by hydrogen atom abstraction from $\mathrm{DMAP}-\mathrm{BH}_{3}$ using di-tertbutyl hyponitrite (TBHN) as a radical initiator (62), could promote the defluorination. $N$-heterocyclic carbene-boryl radical (57), pyridine-boryl radical (62), tributylstannyl radical, and tris(trimethylsilyl)silyl radical were ineffective (table $\mathrm{S} 1$, entries 12-15). Thiophenol ( $\mathrm{PhSH})$ was used as a polarity reversal catalyst $(63,64)$. As shown in Fig. 2, the reaction of trifluoroacetamide $\mathbf{1 a}$ with 1.5 equivalents of $\mathrm{DMAP}^{-\mathrm{BH}_{3}}$ in the presence of $\mathrm{NaH}_{2} \mathrm{PO}_{4} \cdot 2 \mathrm{H}_{2} \mathrm{O}$ (1.2 equiv) as a base in $\mathrm{CH}_{3} \mathrm{CN}$ (Method-1) gave the monohydrodefluorination product 2a in $82 \%$ yield, along with dihydrodefluorination product $\mathbf{3 a}$ in $7 \%$ yield. Compound $\mathbf{3 a}$ was formed as the sole product ( $85 \%$ yield) when increased amounts of $\mathrm{DMAP}^{-\mathrm{BH}_{3}}$ (3 equiv) and $\mathrm{Na}_{2} \mathrm{HPO}_{4} \cdot 12 \mathrm{H}_{2} \mathrm{O}$ (2.4 equiv) in 1,4-dioxane were employed (Method-2). In both protocols, no trihydrodefluorination product was detected. Gram-scale syntheses of $\mathbf{2 a}$ and $\mathbf{3 a}$ were also achieved with good yields.

Both methods show broad substrate scope and good chemoselectivity (Fig. 2). In some cases, minor over-reduction occurred with Method-1 to give $\mathrm{CFH}_{2}$ products, but usually in less than $5 \%$ yields. $N$-Aryl trifluoroacetamides bearing a wide range of functional groups (1)-11) were converted into $\mathrm{CF}_{2} \mathrm{H}$ - and $\mathrm{CFH}_{2}$-containing products with high yields and chemoselectivity, while the presence of an alkene tether $(\mathbf{I m})$ resulted in an inferior yield. Tertiary amide $\mathbf{1 n}$ reacted well under both sets of reaction conditions. For the reactions of pentafluoropropanamides (1o-1s), only the C-F bonds $\alpha$ to the carbonyl group were selectively reduced, and the $\mathrm{CF}_{3}$ group was inert. This result suggests that $\mathrm{C}-\mathrm{F}$ bond cleavage is likely assisted by the adjacent carbonyl moiety. $\mathrm{N}$-Heteroaryls, such as indole (1p) and benzofuran (1r) motifs, were compatible. Monohydrodefluorination of $N$-alkyl pentafluoropanamide $\mathbf{1 s}$ gave $\mathbf{2 s}$ in $44 \%$ yield, but the dihydrodefluorination using Method-2 was unsuccessful, yielding $\mathbf{2 s}$ as the sole product. Both protocols were applied for the insertion of di- and monofluoroacetyl units onto a $\beta$-estradiol system (2t and $\mathbf{3 t}$ ). Incorporation of a trifluoroacetate tether onto the cholesterol framework followed by Method-1 delivered the desired difluoro product $\mathbf{2 u}$, though Method-2 mainly led to hydrolysis and only a trace amount of monofluorinated product was detected.

\section{Controlled defluorinative coupling reactions with alkenes}

Alkenes were then used as the radical trap to capture the resulting $\alpha, \alpha$-difluorocarbonyl radical Int-III. As demonstrated in Fig. 3, the coupling reaction proceeded smoothly, affording a broad range of $\alpha, \alpha$-difluorocarbonyl products. It should be noted that an excess amount of radical initiator was required to maintain high efficiency and di-tert-butyl peroxide (DTBP) was found to be optimal (table S3, entry 6). To enable efficient initiation of DTBP, a higher reaction temperature $\left(120^{\circ} \mathrm{C}\right)$ was necessary. Competing hydrodefluorination products 2 were observed in some cases but in less than $10 \%$ yields. This competing reaction could be further suppressed by adding a slight excess of the alkenes. Although several examples of coupling reactions between $\alpha$-bromo and $\alpha$-iododifluoroacetamides with alkenes have recently been reported $(10,65)$, the present protocol using more easily accessible trifluoroacetamides as precursors is more atom- and step-economical. The coupling reaction proceeded well for styrenes bearing various functional groups (4a-4i). Gram-scale synthesis of $\mathbf{5 a}$ was accomplished in $59 \%$ yield. A series of vinyl ethers $(\mathbf{4 j} \mathbf{j}-\mathbf{4 m})$ and nonactivated alkenes (4n-4p) also underwent coupling, demonstrating broad synthetic applicability. A range of $N$-aryl 
trifluoroacetamides $\mathbf{1}$ could react with styrene to afford $\mathbf{5 q - 5 x}$ in good yields. $\alpha, \alpha$-Difluoro $N$-pyridyl amide $\mathbf{5 y}$ and tertiary amide $\mathbf{5 z}$ were obtained in $65 \%$ and $43 \%$ yields, respectively. However, the coupling reaction of pentafluoropropanamide 10 was unsuccessful, and the competing reduction product 20 was formed in $47 \%$ yield instead. Coupling was also found to proceed efficiently for $\alpha, \alpha, \alpha$-trifluoroacetates, furnishing various $\alpha, \alpha$-difluoroesters $\mathbf{5 a b}-5 \mathbf{a g}$ in synthetically useful yields. This protocol was applied to the modification of drug molecules and naturally occurring bioactive molecules. For example, modification of vorinostat, which is a histone deacetylase inhibitor (66), with the replacement of the oxidation-labile $\alpha$-carbonyl hydrogen atoms with fluorine atoms (difluoro-vorinostat, 6) was synthesized via the coupling of $\mathbf{1 a}$ with commercially available 5 -hexenoic acid followed by amidation with hydroxylamine (Fig. 3D, yellow box). For natural product derivatives containing an alkene moiety, the coupling with a trifluoroacetamide could introduce an $\alpha, \alpha$-difluoroamide moiety (5ai and 5aj). Conversely, amine- and alcohol-containing molecules could insert a trifluoroacetyl group through an initial simple acylation reaction, and the subsequent coupling reaction incorporated a variety of $\alpha, \alpha$-difluoroacetyl functionalities (5ak-5ao). In these transformations, trifluoroacetates participate in the reaction while the simple ester moiety remains intact. Such a recognition is likely due to the different electron property of the carbonyl groups that influences the reactivity with DMAP- $\mathrm{BH}_{2} \bullet$. The connection of two bioactive molecules through an $\alpha, \alpha$-difluoroamide linker (5ap) was also achieved. An attempt to trap the $\alpha, \alpha$-difluorocarbonyl radical with an intramolecular alkene moiety was performed, and the cyclized product was obtained in a low yield along with the detection of deallylation products (see fig. S1).

As shown above, a diverse range of $\alpha, \alpha$-difluorocarbonyl products (2 and 5) were obtained with good yields and selectivity in stage $\mathbf{A}$. We next sought to induce the second $\beta$-C-F bond cleavage and capture the resulting $\alpha$-monofluorocarbonyl radical intermediates with different radical traps to afford densely functionalized $\alpha$-monofluorocarbonyl derivatives. Indeed, as depicted in Fig. 4A, compounds 2 were successfully transformed to products $\mathbf{7}$ via the defluorinative coupling reaction with alkenes $(\mathbf{7 a - 7 k})$. The synthetic utility was demonstrated by a gram-scale synthesis of $\mathbf{7 a}$. This protocol was applicable to the synthesis of monofluorinated bioactive molecules (for $\mathbf{7 l}$ and $\mathbf{7 m}$ ). We next probed the feasibility of a second coupling reaction of difluoro products 5a by using a different alkene as the coupling partner. The reaction was again found to be effective, forming products 8 containing a monofluorinated-tertiary stereogenic center (Fig. 4B) (67), although moderate yields were achieved, along with the recovery of the unreacted $\mathbf{5 a}$.

\section{Synthetic applications}

By taking advantage of the rich chemistry of the carbonyl moiety, the resulting di- and monofluorocarbonyl products are transferable to a broad range of versatile fluorinated building blocks that are of great value in synthetic and medicinal chemistry. For example, the reduction of difluoro amides $\mathbf{2}$ and $\mathbf{5}$ and monofluoro amides $\mathbf{3}$ and $\mathbf{7}$ with the $\mathrm{BH}_{3} \cdot \mathrm{THF}$ complex provided $\beta$-mono- and $\beta$, $\beta$-difluoroamines $\mathbf{9}$ and $\mathbf{1 0}$ in good yields (Fig. 5A). In addition, as depicted in Fig. 5B, 5aa could be readily transformed into various useful difluoro products, such as $\beta, \beta$-difluoroalcohol $\mathbf{1 1}$ and $\mathbf{1 2}$, $\beta, \beta$-difluoroamine 13, and $\alpha, \alpha$-difluoroketone 14. The fluoroalkyl moiety in these products is derived from low-cost trifluoroacetic acid or anhydride.

\section{Mechanistic studies}

To explore the nature of the radical defluorination process, mechanistic experiments and computational studies were conducted. A control experiment showed that no reaction occurred when the radical initiator was omitted (table S1, entry 6 ), confirming the radical nature of this reaction. When alkenes $\mathbf{1 5}$ and $\mathbf{1 7}$ bearing a radical clock (68) were subjected to the coupling reaction conditions, cyclopropane- and cyclobutane ring-opening products $\mathbf{1 6}$ and $\mathbf{1 8}$ were obtained, respectively (Fig. 6A), indicating the intermediacy of difluoroalkyl radical Int-1 in the reaction.

Based on these results, we posit that the defluorination mechanism for $\mathbf{1 a}$ is as follows (Fig. 6, B and C). DMAP- $\mathrm{BH}_{2} \bullet$ is generated from DMAP-BH $\mathrm{BH}_{3}$ using TBHN as a radical initiator (62). The addition of DMAP- $\mathrm{BH}_{2} \bullet$ to the carbonyl oxygen of amide 1a gives Int-2. Then, a SCS process occurs to provide Int-3 with the cleavage of a C-F bond. Although it is difficult to obtain a direct experimental evidence for this process, an analogous reaction of an $\alpha$-fluorothioamide containing a cyclopropyl radical clock provided additional support of SCS (see fig. S4). 1,2-Fluorine radical rearrangement has been posited during the isomerization of perfluorinated radicals (69). However, in our case, DFT calculations revealed that such a 1,2-F migration of Int-2 requires a high activation free energy $\left(\Delta \mathrm{G}^{\ddagger}=23.9 \mathrm{kcal} / \mathrm{mol}\right)$ and is endergonic by $12.0 \mathrm{kcal} / \mathrm{mol}$ (see fig. S8). Thus, this route is considered less feasible. From Int-3, hydrogen atom transfer from $\mathrm{PhSH}$ occurs, and the subsequent hydrolysis affords difluoro product $\mathbf{2 a}$ (Fig. 7B). The resulting thiyl radical then abstracts a hydrogen atom from $\mathrm{DMAP}-\mathrm{BH}_{3}$ to regenerate DMAP- $\mathrm{BH}_{2} \bullet$ and $\mathrm{PhSH}$, thereby propagating the radical chain process $(70)$. When styrene is present, the coupling reaction proceeds preferentially over reduction to give Int-7, which then participates in an analogous polarity reversal catalysis, affording coupling product 5a. When further amounts of DMAP- $-\mathrm{BH}_{3}$ are added to $\mathbf{2 a}$ and $\mathbf{5 a}$, the second SCS occurs, and monofluoro-substituted radicals Int-6 and Int-9 are 
generated. The subsequent reduction or coupling reactions provide monofluoro products $\mathbf{3 a}, \mathbf{7 a}$, and $\mathbf{8 a}$.

To gain deeper insights into the reaction mechanism, DFT calculations were performed at both the (U)M06-2X/6$311+\mathrm{G}(\mathrm{d}, \mathrm{p}) / \mathrm{SMD}\left(\mathrm{CH}_{3} \mathrm{CN}\right) / /(\mathrm{U}) \mathrm{M} 06-2 \mathrm{X} / 6-31+\mathrm{G}(\mathrm{d}, \mathrm{p}) / \mathrm{SMD}\left(\mathrm{CH}_{3} \mathrm{CN}\right)$

(level A) and (U) $\omega \mathrm{B} 97 \mathrm{XD} / 6-311+\mathrm{G}(\mathrm{d}, \mathrm{p}) / \mathrm{SMD}\left(\mathrm{CH}_{3} \mathrm{CN}\right) / /(\mathrm{U}) \mathrm{M} 06-$ $2 \mathrm{X} / 6-31+\mathrm{G}(\mathrm{d}, \mathrm{p}) / \mathrm{SMD}\left(\mathrm{CH}_{3} \mathrm{CN}\right)$ (level $\mathrm{B}$ ) levels of theory (details are provided in the supplementary materials). As the reaction of $\mathbf{~} \mathbf{a}$ could proceed as well in the absence of any additive (table S1, entry 1), DFT calculations were carried out using this reaction as an exemplary model. Figure 7A shows the energy profile of the monohydrodefluorination of $\mathbf{1 a}$ at level A. The addition of the 4-aminopyridine-boryl radical to $\mathbf{1 a}$ is exergonic to give a stabilized radical Int-2. Then, SCS of Int-2 occurs via TS-II-1a with an energy barrier of $20.6 \mathrm{kcal} / \mathrm{mol}$, which is found to be the rate-determining step. An alternative SCS process of the deprotonated species derived from Int-2 is also possible with a surmountable energy barrier (see figs. S6 and S7). However, when the reactions of tertiary amide $\mathbf{~ n n}$ and acetate $\mathbf{1 b b}$ both lacking acidic protons were also examined without any additive, no defluorination was observed (table S2, entry 2 and table S5, entry 2). DFT calculations imply that direct fluoride eliminations from Int-2-1n and Int-2-1bb are highly endergonic $(\Delta \mathrm{G}=24.5 \mathrm{kcal} / \mathrm{mol}$ at level A for Int-2-1n, $\Delta \mathrm{G}=29.0 \mathrm{kcal} / \mathrm{mol}$ at level $\mathrm{A}$ for Int-2-1bb: see figs. S18 and S22). A scan of C-F bond length in these two intermediates indicates that there is no maximum (see figs. S19 and S23). Further investigations revealed that the presence of alkali metal salts is indispensable to promote the defluorination and $\mathrm{NaH}_{2} \mathrm{PO}_{4}$ was found to be optimal (table S2, entries 5-12 and table S5, entries 4-13). DFT calculations at level $\mathrm{A}$ and level $\mathrm{B}$ both suggest that the addition of either the naked $\mathrm{Na}^{+}$or the $\mathrm{Na}^{+}$in $\mathrm{NaH}_{2} \mathrm{PO}_{4}$ favors the loss of fluoride anion, rendering the SCS energetically possible (Fig. 7B and figs. S20, S21, S24, and S25). Moreover, for the reaction of N-H amide $\mathbf{1 a}$, the activation free energies for the SCS of Int-2 also decrease when the naked $\mathrm{Na}^{+}$(Level A: $\Delta \mathrm{G}^{\ddagger}=10.7$ $\mathrm{kcal} / \mathrm{mol}$, fig. S10) or the $\mathrm{Na}^{+}$in $\mathrm{NaH}_{2} \mathrm{PO}_{4}$ (Level A: $\Delta \mathrm{G}^{\ddagger}=9.6$ $\mathrm{kcal} / \mathrm{mol}$, fig. S11) is present as compared to the one without any additive (Level A: $\Delta \mathrm{G}^{\ddagger}=20.6 \mathrm{kcal} / \mathrm{mol}$ ). Experimental results showed that the addition of $\mathrm{NaH}_{2} \mathrm{PO}_{4}$ is beneficial to accelerate the reaction and improve the product yield (table S1, entries 1-4), which is consistent with the computational studies. These results hint that the $\mathrm{Na}^{+}$most likely plays an important role to assist the cleavage of $\mathrm{C}-\mathrm{F}$ bond in these reactions (30). The reaction of Int-3 with styrene has been also calculated (fig. S12). The results show that the addition step is irreversible and a lower activation energy (Level $A, \Delta G^{\ddagger}=$ $10.8 \mathrm{kcal} / \mathrm{mol}$ ) than that of the competing hydrogen atom transfer from $\mathrm{PhSH}$ (Level $\mathrm{A}, \Delta \mathrm{G}^{\ddagger}=12.7 \mathrm{kcal} / \mathrm{mol}$ ) is required, thus rendering the coupling reaction predominant.

Next, we analyzed the charge and electron spin transfer in the SCS of Int-2 with Multiwfn (Fig. 7C) (71). In TS-II-1a, the departing fluoride possesses a negative charge $(-0.73)$ and a relatively low spin density (0.07), implying that the cleavage of the $\mathrm{C}-\mathrm{F}$ bond is heterolytic. The fluoride is highly basic in this medium and deprotonates the cation. In Int-2, the majority of the spin density is located on the $\alpha$-carbon atom (0.53). During the SCS, the spin density shifts gradually to the adjacent $\beta$-carbon and $\mathrm{N}$ atoms and the spin population is mainly divided between the $\beta$-carbon atom (0.47) and $\mathrm{N}$ atom $(0.26)$ in the resulting Int-3.

DFT calculations at level A and level B both suggest that the SCS of $2 \mathbf{a}$ bearing two fluorine atoms is kinetically and thermodynamically more favorable than that of $\mathbf{1 a}$, and the SCS of $\mathbf{3 a}$ is nearly a barrierless process (Fig. 7D). This trend is in accordance with the gradually decreasing BDE of the $\mathrm{C}-\mathrm{F}$ bonds from $\mathbf{1 a}$ to $\mathbf{3 a}$ (5). However, in our protocols, the defluorination proceeds with an inverse reactivity. Namely, the reaction of trifluoromethyl $\mathbf{1 a}$ is more favorable than that of difluoromethyl $\mathbf{2 a}$ and much more favorable than that of monofluoromethyl 3a. This selectivity is probably due to the declining reactivity of DMAP- $\mathrm{BH}_{2} \bullet$ toward the addition to the defluorinated products (Fig. 7E). DFT calculations reveal that the reaction between DMAP- $\mathrm{BH}_{2} \bullet$ and $\mathbf{1 a}$ is exergonic with an activation free energy of $7.9 \mathrm{kcal} / \mathrm{mol}$ (level A) and $8.3 \mathrm{kcal} / \mathrm{mol}$ (level B), whereas the reactions with $\mathbf{2 a}$ $(9.2 \mathrm{kcal} / \mathrm{mol}$ at level A, $8.9 \mathrm{kcal} / \mathrm{mol}$ at level B) and $\mathbf{3 a}(11.1$ $\mathrm{kcal} / \mathrm{mol}$ at level A, $10.4 \mathrm{kcal} / \mathrm{mol}$ at level B) have higher energy barriers. This reactivity trend is attributed to the increasing singly occupied molecular orbital (SOMO)/lowest unoccupied molecular orbital (LUMO) gaps between DMAP$\mathrm{BH}_{2} \bullet$ and the substrates. From $\mathbf{1 a}$ to $\mathbf{3 a}$, as the number of fluorine atoms decreased, the LUMO energies increased $(-0.22 \mathrm{eV}$ for $\mathbf{1 a},-0.10 \mathrm{eV}$ for $\mathbf{2 a}$, and $0.20 \mathrm{eV}$ for $\mathbf{3 a}$, fig. S26), thus increasing the SOMO/LUMO gaps. These reactivity characteristics are crucial to ensure exquisite chemoselectivity during defluorination.

We anticipate that the spin-center shift strategy reported here will be applicable to other carbon-heteroatom bond (i.e., $\mathrm{C}-\mathrm{O}, \mathrm{C}-\mathrm{N}, \mathrm{C}-\mathrm{Cl}$, etc.) scissions and could enable highly economical syntheses.

\section{REFERENCES AND NOTES}

1. E. P. Gillis, K. J. Eastman, M. D. Hill, D. J. Donnelly, N. A. Meanwell, Applications of fluorine in medicinal chemistry. J. Med. Chem. 58, 8315-8359 (2015) doi:10.1021/acs.jmedchem.5b00258 Medline

2. Y. Zhou, J. Wang, Z. Gu, S. Wang, W. Zhu, J. L. Aceña, V. A. Soloshonok, K. Izawa, H. Liu, Next generation of fluorine-containing pharmaceuticals, compounds currently in phase II-III clinical trials of major pharmaceutical companies: New structural trends and therapeutic areas. Chem. Rev. 116, 422-518 (2016). doi:10.1021/acs.chemrev.5b00392 Medline

3. T. Fujiwara, D. O'Hagan, Successful fluorine-containing herbicide agrochemicals. J. Fluor. Chem. 167, 16-29 (2014). doi:10.1016/j.jfluchem.2014.06.014

4. R. Berger, G. Resnati, P. Metrangolo, E. Weber, J. Hulliger, Organic fluorine compounds: A great opportunity for enhanced materials properties. Chem. Soc. Rev. 40, 3496-3508 (2011). doi:10.1039/c0cs00221f Medline 
5. D. O'Hagan, Understanding organofluorine chemistry. An introduction to the C-F bond. Chem. Soc. Rev. 37, 308-319 (2008). doi:10.1039/B711844A Medline

6. W. K. Hagmann, The many roles for fluorine in medicinal chemistry. J. Med. Chem. 51, 4359-4369 (2008). doi:10.1021/im800219f Medline

7. T. Furuya, A. S. Kamlet, T. Ritter, Catalysis for fluorination and trifluoromethylation. Nature 473, 470-477 (2011). doi:10.1038/nature10108 Medline

8. X. Yang, T. Wu, R. J. Phipps, F. D. Toste, Advances in catalytic enantioselective fluorination, mono-, di-, and trifluoromethylation, and trifluoromethylthiolation reactions. Chem. Rev. 115, 826-870 (2015). doi:10.1021/cr500277b Medline

9. C. Ni, M. Hu, J. Hu, Good partnership between sulfur and fluorine: Sulfur-based fluorination and fluoroalkylation reagents for organic synthesis. Chem. Rev. 115, 765-825 (2015). doi:10.1021/cr5002386 Medline

10. Z. Feng, Y.-L. Xiao, X. Zhang, Transition-metal (Cu, Pd, Ni)-catalyzed difluoroalkylation via cross-coupling with difluoroalkyl halides. Acc. Chem. Res. 51, 2264-2278 (2018). doi:10.1021/acs.accounts.8b00230 Medline

11. V. Rauniyar, A. D. Lackner, G. L. Hamilton, F. D. Toste, Asymmetric electrophilic fluorination using an anionic chiral phase-transfer catalyst. Science 334, 16811684 (2011). doi:10.1126/science.1213918 Medline

12. Y. Fujiwara, J. A. Dixon, F. O'Hara, E. D. Funder, D. D. Dixon, R. A. Rodriguez, R. D. Baxter, B. Herlé, N. Sach, M. R. Collins, Y. Ishihara, P. S. Baran, Practical and innate carbon-hydrogen functionalization of heterocycles. Nature 492, 95-99 (2012). doi:10.1038/nature11680 Medline

13. J. Saadi, H. Wennemers, Enantioselective aldol reactions with masked fluoroacetates. Nat. Chem. 8, 276-280 (2016). doi:10.1038/nchem.2437Medline

14. Z. Feng, Q.-Q. Min, X.-P. Fu, L. An, X. Zhang, Chlorodifluoromethane-triggered formation of difluoromethylated arenes catalysed by palladium. Nat. Chem. 9 , 918-923 (2017). doi:10.1038/nchem.2746 Medline

15. P. Adler, C. J. Teskey, D. Kaiser, M. Holy, H. H. Sitte, N. Maulide, $\alpha$-Fluorination of carbonyls with nucleophilic fluorine. Nat. Chem. 11, 329-334 (2019). doi:10.1038/s41557-019-0215-z Medline

16. R. R. Merchant, J. T. Edwards, T. Qin, M. M. Kruszyk, C. Bi, G. Che, D.-H. Bao, W. Qiao, L. Sun, M. R. Collins, O. O. Fadeyi, G. M. Gallego, J. J. Mousseau, P. Nuhant, P. S. Baran, Modular radical cross-coupling with sulfones enables access to $\mathrm{sp}^{3}-$ rich (fluoro)alkylated scaffolds. Science 360, 75-80 (2018). doi:10.1126/science.aar7335 Medline

17. H. Amii, K. Uneyama, C-F bond activation in organic synthesis. Chem. Rev. 109 , 2119-2183 (2009). doi:10.1021/cr800388c Medline

18. T. Ahrens, J. Kohlmann, M. Ahrens, T. Braun, Functionalization of fluorinated molecules by transition-metal-mediated C-F bond activation to access fluorinated building blocks. Chem. Rev. 115, 931-972 (2015). doi:10.1021/cr500257c Medline

19. Q. Shen, Y.-G. Huang, C. Liu, J.-C. Xiao, Q.-Y. Chen, Y. Guo, Review of recent advances in C-F bond activation of aliphatic fluorides. J. Fluor. Chem. 179, 14-22 (2015). doi:10.1016/jiffluchem.2015.07.007

20. F. Jaroschik, Picking One out of Three: Selective single C-F activation in trifluoromethyl groups. Chem. Eur. J. 24, 14572-14582 (2018). doi:10.1002/chem.201801702 Medline

21. X. Ma, Q. Song, Recent progress on selective deconstructive modes of halodifluoromethyl and trifluoromethyl-containing reagents. Chem. Soc. Rev. 49 9197-9219 (2020). doi:10.1039/DOCS00604A Medline

22. K. Uneyama, H. Amii, A review of Mg metal-promoted C-F bond activation; a reliable synthetic approach to difluorinated organic compounds. J. Fluor. Chem. 114, 127-131 (2002). doi:10.1016/S0022-1139(02)00039-8

23. K. Uneyama, G. Mizutani, K. Maeda, T. Kato, Electroreductive Defluorination of Trifluoromethyl Ketones and Trifluoroacetic Acid Derivatives. J. Org. Chem. 64, 6717-6723 (1999). doi:10.1021/i0990571d Medline

24. G. Blond, T. Billard, B. R. Langlois, Generation and use of an equivalent of difluoroacetamide or difluoroacetate anions. Chem. Eur. J. 8, 2917-2922 (2002). doi:10.1002/1521-3765(20020703)8:13<2917:AID-CHEM2917>3.0.C0;2-M Medline

25. S. Yoshida, K. Shimomori, Y. Kim, T. Hosoya, Single C-F bond cleavage of trifluoromethylarenes with an ortho-silyl Group. Angew. Chem. Int. Ed. 55, 1040610409 (2016). doi:10.1002/anie.201604776 Medline

26. T. Fujita, K. Fuchibe, J. Ichikawa, Transition-metal-mediated and -catalyzed C-F bond activation by fluorine elimination. Angew. Chem. Int. Ed. 58, 390-402 (2019). doi:10.1002/anie.201805292 Medline
27. D. Mandal, R. Gupta, A. K. Jaiswal, R. D. Young, Frustrated Lewis-pair-meditated selective single fluoride substitution in trifluoromethyl Groups. J. Am. Chem. Soc. 142, 2572-2578 (2020). doi:10.1021/jacs.9b12167 Medline

28. M. M. Wade Wolfe, J. P. Shanahan, J. W. Kampf, N. K. Szymczak, Defluorinative functionalization of Pd(II) fluoroalkyl complexes. J. Am. Chem. Soc. 142, 1869818705 (2020). doi:10.1021/jacs.0c09505 Medline

29. M. D. Levin, T. Q. Chen, M. E. Neubig, C. M. Hong, C. A. Theulier, I. J. Kobylianskii, M. Janabi, J. P. O'Neil, F. D. Toste, A catalytic fluoride-rebound mechanism for $\mathrm{C}\left(\mathrm{sp}^{3}\right)-\mathrm{CF}_{3}$ bond formation. Science 356, 1272-1276 (2017) doi:10.1126/science aan1411 Medline

30. T. W. Butcher, J. L. Yang, W. M. Amberg, N. B. Watkins, N. D. Wilkinson, J. F. Hartwig, Desymmetrization of difluoromethylene groups by C-F bond activation. Nature 583, 548-553 (2020). doi:10.1038/s41586-020-2399-1 Medline

31. G. K. Surya Prakash, J. Hu, G. A. Olah, Facile preparation of di- and monofluoromethyl ketones from trifluoromethyl ketones via fluorinated enol silyl ethers. J. Fluor. Chem. 112, 355-360 (2001). doi:10.1016/S0022-1139(01)005358

32. J. Wettergren, T. Ankner, G. Hilmersson, Selective $\alpha$-defluorination of polyfluorinated esters and amides using $\mathrm{Sml}_{2} / \mathrm{Et}_{3} \mathrm{~N} / \mathrm{H}_{2} \mathrm{O}$. Chem. Commun. 46, 7596-7597 (2010). doi:10.1039/c0cc02009e Medline

33. H. Iwamoto, H. Imiya, M. Ohashi, S. Ogoshi, Cleavage of $\mathrm{C}\left(\mathrm{sp}^{3}\right)-\mathrm{F}$ bonds in trifluoromethylarenes using a bis(NHC)nickel(0) complex. J. Am. Chem. Soc. 142, 19360-19367 (2020). doi:10.1021/jacs.0c09639 Medline

34. K. Chen, N. Berg, R. Gschwind, B. König, Selective single C( $\left(\mathrm{sp}^{3}\right)-\mathrm{F}$ bond cleavage in trifluoromethylarenes: Merging visible-light catalysis with Lewis acid activation. J. Am. Chem. Soc. 139, 18444-18447 (2017). doi:10.1021/jacs.7b10755 Medline

35. D. B. Vogt, C. P. Seath, H. Wang, N. T. Jui, Selective C-F functionalization of unactivated trifluoromethylarenes. J. Am. Chem. Soc. 141, 13203-13211 (2019). doi:10.1021/jacs.9b06004 Medline

36. H. Wang, N. T. Jui, Catalytic defluoroalkylation of trifluoromethylaromatics with unactivated alkenes. J. Am. Chem. Soc. 140, 163-166 (2018). doi:10.1021/iacs.7b12590 Medline

37. C. Luo, J. S. Bandar, Selective defluoroallylation of trifluoromethylarenes. J. Am. Chem. Soc. 141, 14120-14125 (2019). doi:10.1021/iacs.9b07766 Medline

38. J. B. I. Sap, N. J. W. Straathof, T. Knauber, C. F. Meyer, M. Médebielle, L. Buglioni, C. Genicot, A. A. Trabanco, T. Noël, C. W. Am Ende, V. Gouverneur, Organophotoredox hydrodefluorination of trifluoromethylarenes with translational applicability to drug discovery. J. Am. Chem. Soc. 142, 9181-9187 (2020). doi:10.1021/jacs.0c03881 Medline

39. P. Wessig, O. Muehling, Spin-center shift (SCS) - A versatile concept in bological and synthetic chemistry. Eur. J. Org. Chem. 2007, 2219-2232 (2007). doi:10.1002/ejoc.200600915

40. B. Halliwell, J. M. C. Gutteridge, Free Radicals in Biology and Medicine 5th edn. (Oxford University Press, 2015).

41. J. Li, W. P. Griffith, I. Davis, I. Shin, J. Wang, F. Li, Y. Wang, D. J. Wherritt, A. Liu, Cleavage of a carbon-fluorine bond by an engineered cysteine dioxygenase. Nat. Chem. Biol. 14, 853-860 (2018). doi:10.1038/s41589-018-0085-5 Medline

42. H. Eklund, U. Uhlin, M. Färnegårdh, D. T. Logan, P. Nordlund, Structure and function of the radical enzyme ribonucleotide reductase. Prog. Biophys. Mol. Biol. 77, 177-268 (2001). doi:10.1016/S0079-6107(01)00014-1 Medline

43. A. L. J. Beckwith, D. Crich, P. J. Duggan, Q. Yao, Chemistry of beta-(acyloxy)alkyl and beta-(phosphatoxy)alkyl radicals and related species: Radical and radical ionic migrations and fragmentations of carbon-oxygen bonds. Chem. Rev. 97, 3273-3312 (1997). doi:10.1021/cr950207o Medline

44. M. Newcomb, J. H. Horner, P. O. Whitted, D. Crich, X. Huang, Q. Yao, H. Zipse, $\beta$ Phosphatoxyalkyl radical reactions:Competing phosphate migration and phosphoric acid elimination from a radical cation-phosphate anion pair formed by heterolytic fragmentation. J. Am. Chem. Soc. 121, 10685-10694 (1999). doi:10.1021/ia991012r

45. H. Zipse, The methylenology principle: How radicals influence the course of ionic reactions. Acc. Chem. Res. 32, 571-578 (1999). doi:10.1021/ar980035s

46. P. Wessig, O. Mühling, A new photochemical route to cyclopropanes. Angew. Chem. Int. Ed. 40, 1064-1065 (2001). doi:10.1002/1521 3773(20010316)40:6<1064:AID-ANIE10640>3.0.C0:2-5 Medline 
47. J. H. Horner, L. Bagnol, M. Newcomb, Kinetics of radical heterolysis reactions forming alkene radical cations. J. Am. Chem. Soc. 126, 14979-14987 (2004). doi:10.1021/ja046089g Medline

48. H. Fuse, H. Nakao, Y. Saga, A. Fukatsu, M. Kondo, S. Masaoka, H. Mitsunuma, M. Kanai, Photocatalytic redox-neutral hydroxyalkylation of N-heteroaromatics with aldehydes. Chem. Sci. 11, 12206-12211 (2020). doi:10.1039/DOSC04114A

49. J. Jin, D. W. C. MacMillan, Alcohols as alkylating agents in heteroarene C-H functionalization. Nature 525, 87-90 (2015). doi:10.1038/nature14885 Medline

50. E. D. Nacsa, D. W. C. MacMillan, Spin-center shift-enabled direct enantioselective $\alpha$-benzylation of aldehydes with alcohols. J. Am. Chem. Soc. 140, 3322-3330 (2018). doi:10.1021/jacs.7b12768 Medline

51. B. Bieszczad, L. A. Perego, P. Melchiorre, Photochemical C-H hydroxyalkylation of quinolines and isoquinolines. Angew. Chem. Int. Ed. 58, 16878-16883 (2019). doi:10.1002/anie.201910641 Medline

52. J. Dong, Z. Wang, X. Wang, H. Song, Y. Liu, Q. Wang, Ketones and aldehydes as alkyl radical equivalents for $\mathrm{C}-\mathrm{H}$ functionalization of heteroarenes. Sci. Adv. 5 , eaax9955 (2019). doi:10.1126/sciadv. aax9955 Medline

53. M. A. Ashley, T. Rovis, Photoredox-catalyzed deaminative alkylation via C-N bond activation of primary amines. J. Am. Chem. Soc. 142, 18310-18316 (2020). doi:10.1021/jacs.0c08595 Medline

54. Y. Laot, L. Petit, S. Z. Zard, Synthesis of fluoroazaindolines by an uncommon radical ipso substitution of a carbon-fluorine bond. Org. Lett. 12, 3426-3429 (2010). doi:10.1021/ol101240f Medline

55. F.-L. Zhang, Y.-F. Wang, in Science of Synthesis: Advances in Organoboron Chemistry Towards Organic Synthesis, E. Fernández, Ed. (Thieme, Stuttgart, 2019), pp. 355-392.

56. T. Taniguchi, Boryl radical addition to multiple bonds in organic synthesis. Eur. J. Org. Chem. 2019, 6308-6319 (2019). doi:10.1002/ejoc.201901010

57. S.-H. Ueng, M. M. Brahmi, E. Derat, L. Fensterbank, E. Lacôte, M. Malacria, D. P. Curran, Complexes of borane and $\mathrm{N}$-heterocyclic carbenes: A new class of radical hydrogen atom donor. J. Am. Chem. Soc. 130, 10082-10083 (2008). doi:10.1021/ja804150k Medline

58. S.-C. Ren, F.-L. Zhang, J. Qi, Y.-S. Huang, A.-Q. Xu, H.-Y. Yan, Y.-F. Wang, Radical borylation/cyclization cascade of 1,6-enynes for the synthesis of boron-handled hetero- and carbocycles. J. Am. Chem. Soc. 139, 6050-6053 (2017). doi:10.1021/jacs.7b01889 Medline

59. C. Wu, X. Hou, Y. Zheng, P. Li, D. Lu, Electrophilicity and nucleophilicity of boryl radicals. J. Org. Chem. 82, 2898-2905 (2017). doi:10.1021/acs.joc.6b02849 Medline

60. S.-H. Ueng, A. Solovyev, X. Yuan, S. J. Geib, L. Fensterbank, E. Lacôte, M. Malacria, M. Newcomb, J. C. Walton, D. P. Curran, N-heterocyclic carbene boryl radicals: A new class of boron-centered radical. J. Am. Chem. Soc. 131, 11256-11262 (2009). doi:10.1021/ja904103x Medline

61. W. Dai, T. R. McFadden, D. P. Curran, H. A. Früchtl, J. C. Walton, 5-Endo cyclizations of NHC-boraallyl radicals bearing ester substituents: Characterization of derived 1,2-oxaborole radicals and boralactones. J. Am. Chem. Soc. 140, 15868-15875 (2018). doi:10.1021/jacs.8b09288 Medline

62. J. Lalevée, N. Blanchard, M.-A. Tehfe, A.-C. Chany, J.-P. Fouassier, New boryl radicals derived from $\mathrm{N}$-heteroaryl boranes: Generation and reactivity. Chem. Eur. J. 16, 12920-12927 (2010). doi:10.1002/chem.201001440 Medline

63. F. Dénès, M. Pichowicz, G. Povie, P. Renaud, Thiyl radicals in organic synthesis. Chem. Rev. 114, 2587-2693 (2014). doi:10.1021/cr400441m Medline

64. B. P. Roberts, Polarity-reversal catalysis of hydrogen-atom abstraction reactions: Concepts and applications in organic chemistry. Chem. Soc. Rev. 28, 25-35 (1999). doi:10.1039/a804291h

65. W. Huang, W. Chen, G. Wang, J. Li, X. Cheng, G. Li, Thiyl-radical-catalyzed photoreductive hydrodifluoroacetamidation of alkenes with Hantzsch ester as a multifunctional reagent. ACS Catal. 6, 7471-7474 (2016). doi:10.1021/acscatal. 6 b02420

66. B. S. Mann, J. R. Johnson, M. H. Cohen, R. Justice, R. Pazdur, FDA approval summary: Vorinostat for treatment of advanced primary cutaneous T-cell lymphoma. Oncologist 12, 1247-1252 (2007). doi:10.1634/theoncologist.12-101247 Medline
67. Y. Zhu, J. Han, J. Wang, N. Shibata, M. Sodeoka, V. A. Soloshonok, J. A. S. Coelho, F. D. Toste, Modern approaches for asymmetric construction of carbon-fluorine quaternary stereogenic centers: Synthetic challenges and pharmaceutical needs. Chem. Rev. 118, 3887-3964 (2018). doi:10.1021/acs.chemrev.7b00778 Medline

68. D. Griller, K. U. Ingold, Free-radical clocks. Acc. Chem. Res. 13, 317-323 (1980). doi:10.1021/ar50153a004

69. D. J. Van Hoomissen, S. Vyas, 1,2-Fluorine radical rearrangements: Isomerization events in perfluorinated radicals. J. Phys. Chem. A 121, 8675-8687 (2017). do::10.1021/acs.jpca.7b08895 Medline

70. X. Pan, E. Lacôte, J. Lalevée, D. P. Curran, Polarity reversal catalysis in radical reductions of halides by N-heterocyclic carbene boranes. J. Am. Chem. Soc. 134 5669-5674 (2012). doi:10.1021/ja300416f Medline

71. T. Lu, F. Chen, Multiwfn: A multifunctional wavefunction analyzer. J. Comput. Chem. 33, 580-592 (2012). doi:10.1002/icc.22885 Medline

72. C. Y. Legault, CYLview, 1.0b. Université de Sherbrooke, 2009; www.cylview.org.

73. Y.-J. Yu, F.-L. Zhang, T.-Y. Peng, C.-L. Wang, J. Cheng, C. Chen, K. N. Houk, Y.-F. Wang, Sequential $\mathrm{C}-\mathrm{F}$ bond functionalizations of trifluoroacetamides and trifluoroacetates via spin-center shifts, Zenodo (2021) https://doi.org/10.5281/zenodo.4510886.

74. M. M. Brahmi, J. Monot, M. Desage-EI Murr, D. P. Curran, L. Fensterbank, E. Lacôte, M. Malacria, Preparation of NHC borane complexes by Lewis base exchange with amine- and phosphine-boranes. J. Org. Chem. 75, 6983-6985 (2010). doi:10.1021/iol01301d Medline

75. P. Veeraraghavan Ramachandran, A. S. Kulkarni, Y. Zhao, J. Mei, Amine-boranes bearing borane-incompatible functionalities: Application to selective amine protection and surface functionalization. Chem. Commun. 52, 11885-11888 (2016). doi:10.1039/C6CC06031E Medline

76. J. Lalevée, N. Blanchard, A.-C. Chany, M.-A. Tehfe, X. Allonas, J.-P. Fouassier, Effect of Lewis base coordination on boryl radical reactivity: Investigation using laser flash photolysis and kinetic ESR. J. Phys. Org. Chem. 22, 986-993 (2009). doi:10.1002/poc.1549

77. J. Emri, B. Győri, A new method for the synthesis of cyanohydroborates and cyanoborane complexes. J. Chem. Soc. Chem. Commun. 1983, 1303-1304 (1983). doi:10.1039/C39830001303

78. M. Noshita, Y. Shimizu, H. Morimoto, T. Ohshima, Diethylenetriamine-Mediated Direct Cleavage of Unactivated Carbamates and Ureas. Org. Lett. 18, 6062-6065 (2016). doi:10.1021/acs.orglett.6b03016 Medline

79. J. Schoepfer, B. Gay, G. Caravatti, C. Garcia-Echeverria, H. Fretz, J. Rahuel, P. Furet, Structure-based design of peptidomimetic ligands of the Grb2-SH2 domain. Bioorg. Med. Chem. Lett. 8, 2865-2870 (1998). doi:10.1016/S0960894X(98)00513-7 Medline

80. D. E. Uehling, K. H. Donaldson, D. N. Deaton, C. E. Hyman, E. E. Sugg, D. G. Barrett, R. G. Hughes, B. Reitter, K. K. Adkison, M. E. Lancaster, F. Lee, R. Hart, M. A. Paulik, B. W. Sherman, T. True, C. Cowan, Synthesis and evaluation of potent and selective $\beta(3)$ adrenergic receptor agonists containing acylsulfonamide, sulfonylsulfonamide, and sulfonylurea carboxylic acid isosteres. J. Med. Chem. 45, 567-583 (2002). doi:10.1021/im0101500 Medline

81. D. Kalia, S. P. Pawar, J. S. Thopate, Stable and Rapid Thiol Bioconjugation by LightTriggered Thiomaleimide Ring Hydrolysis. Angew. Chem. Int. Ed. 56, 1885-1889 (2017). doi:10.1002/anie.201609733 Medline

82. G. Bianchini, M. Aschi, G. Cavicchio, M. Crucianelli, S. Preziuso, C. Gallina, A Nastari, E. Gavuzzo, F. Mazza, Design, modelling, synthesis and biological evaluation of peptidomimetic phosphinates as inhibitors of matrix metalloproteinases MMP-2 and MMP-8. Bioorg. Med. Chem. 13, 4740-4749 (2005). doi:10.1016/i.bmc.2005.04.079 Medline

83. W. Ding, Z.-H. Jiang, P. Wu, L. Xu, X. Wei, Resin glycosides from the aerial parts of Operculina turpethum. Phytochemistry 81, 165-174 (2012) doi:10.1016/i.phytochem.2012.05.010 Medline

84. Y. Shi, J. T. Koh, Functionally orthogonal ligand-receptor pairs for the selective regulation of gene expression generated by manipulation of charged residues at the ligand-receptor interface of ER $\alpha$ and ER $\beta$. J. Am. Chem. Soc. 124, 6921-6928 (2002). doi:10.1021/ia016897x Medline

85. M. Ke, Q. Song, Copper/B2pin 2 -catalyzed C-H difluoroacetylation-cycloamidation of anilines leading to the formation of 3,3-difluoro-2-oxindoles. Chem. Commun. 53, 2222-2225 (2017). doi:10.1039/C6CC09643C Medline 
86. T. Nishikata, S. Ishida, R. Fujimoto, Site-Selective Tertiary Alkyl-Fluorine Bond Formation from $\alpha$-Bromoamides Using a Copper/CsF Catalyst System. Angew. Chem. Int. Ed. 55, 10008-10012 (2016). doi:10.1002/anie.201603426 Medline

87. S. Koeller, C. Thomas, F. Peruch, A. Deffieux, S. Massip, J.-M. Léger, J.-P. Desvergne, A. Milet, B. Bibal, $\alpha$-Halogenoacetanilides as hydrogen-bonding organocatalysts that activate carbonyl bonds: Fluorine versus chlorine and bromine. Chem. Eur. J. 20, 2849-2859 (2014). doi:10.1002/chem.201303662 Medline

88. T. Fuchigami, S. Ichikawa, Electrolytic Reactions of Fluoroorganic Compounds. 14. Regioselective Anodic Methoxylation of N-(Fluoroethyl)amines. Preparation of Highly Useful Fluoroalkylated Building Blocks. J. Org. Chem. 59, 607-615 (1994). doi:10.1021/i000082a018

89. E. Briard, V. W. Pike, Substitution-reduction: An alternative process for the [18F]N(2-fluoroethylation) of anilines. J. Labelled Comp. Radiopharm. 47, 217-232 (2004). doi:10.1002/iler.816

90. Y.-J. Yu, F.-L. Zhang, J. Cheng, J.-H. Hei, W.-T. Deng, Y.-F. Wang, Lewis Base-Boryl Radicals Enabled the Desulfurizative Reduction and Annulation of Thioamides. Org. Lett. 20, 24-27 (2018). doi:10.1021/acs.orglett.7b03201 Medline

91. E. Byun, B. Hong, K. A. De Castro, M. Lim, H. Rhee, One-pot reductive mono-Nalkylation of aniline and nitroarene derivatives using aldehydes. J. Org. Chem. 72 , 9815-9817 (2007). doi:10.1021/jo701503g Medline

92. M. J. Frisch, G. W. Trucks, H. B. Schlegel, G. E. Scuseria, M. A. Robb, J. R. Cheeseman, G. Scalmani, V. Barone, G. A. Petersson, H. Nakatsuji, X. Li, M. Caricato, A. V. Marenich, J. Bloino, B. G. Janesko, R. Gomperts, B. Mennucci, H. P. Hratchian, J. V. Ortiz, A. F. Izmaylov, J. L. Sonnenberg, F. Williams, F. Ding, F. Lipparini, F. Egidi, J. Goings, B. Peng, A. Petrone, T. Henderson, D. Ranasinghe, V. G. Zakrzewski, J. Gao, N. Rega, G. Zheng, W. Liang, M. Hada, M. Ehara, K. Toyota, R. Fukuda, J. Hasegawa, M. Ishida, T. Nakajima, Y. Honda, O. Kitao, H. Nakai, T. Vreven, K. Throssell, J. A. Montgomery Jr., J. E. Peralta, F. Ogliaro, M. J. Bearpark, J. J. Heyd, E. N. Brothers, K. N. Kudin, V. N. Staroverov, T. A. Keith, R. Kobayashi, J. Normand, K. Raghavachari, A. P. Rendell, J. C. Burant, S. S. Iyengar, J. Tomasi, M. Cossi, J. M. Millam, M. Klene, C. Adamo, R. Cammi, J. W. Ochterski, R. L. Martin, K. Morokuma, O. Farkas, J. B. Foresman, D. J. Fox, Gaussian 16, Revision C.01, Wallingford CT, 2016.

93. Y. Zhao, D. G. Truhlar, The M06 suite of density functionals for main group thermochemistry, thermochemical kinetics, noncovalent interactions, excited states, and transition elements: Two new functionals and systematic testing of four M06-class functionals and 12 other functionals. Theor. Chem. Acc. 120, 215241 (2008). doi:10.1007/s00214-007-0310-x

94. Y. Zhao, D. G. Truhlar, Density functionals with broad applicability in chemistry. Acc. Chem. Res. 41, 157-167 (2008). do:10.1021/ar700111a Medline

95. W. J. Hehre, L. Radom, P. R. Schleyer, J. A. Pople, Ab Initio Molecular Orbital Theory (Wiley, New York, 1986).

96. A. V. Marenich, C. J. Cramer, D. G. Truhlar, Universal solvation model based on solute electron density and on a continuum model of the solvent defined by the bulk dielectric constant and atomic surface tensions. J. Phys. Chem. B113, 63786396 (2009). doi:10.1021/pip810292n Medline

97. J.-D. Chai, M. Head-Gordon, Long-range corrected hybrid density functionals with damped atom-atom dispersion corrections. Phys. Chem. Chem. Phys. 10, 66156620 (2008). doi:10.1039/b810189b Medline

98. J. A. Montgomery Jr., M. J. Frisch, J. W. Ochterski, G. A. Petersson, A complete basis set model chemistry. VI. Use of density functional geometries and frequencies. J. Chem. Phys. 110, 2822-2827 (1999). doi:10.1063/1.477924

99. J. A. Montgomery Jr., M. J. Frisch, J. W. Ochterski, G. A. Petersson, A complete basis set model chemistry. VII. Use of the minimum population localization method. J. Chem. Phys. 112, 6532-6542 (2000). doi:10.1063/1.481224

\section{ACKNOWLEDGMENTS}

We thank Prof. Shunsuke Chiba (Nanyang Technological University, Singapore) and Samir Z. Zard (Ecole Polytechnique, France) for valuable discussions on the reaction mechanism. Funding: We thank the National Natural Science Foundation of China (21672195, 21702201, and 21971226) and the Fundamental Research Funds for the Central Universities (WK2060000017) for financial support. Support of KNH was from the US National Science Foundation (CHE1764328). The numerical calculations in this study have been done on the supercomputing system in the Super-computing Centre of the University of Science and Technology of China. Author contributions: Y.-F.W. conceived the project and directed the research. Y.-J.Y. conducted the majority of experiments. T.-Y.P., C.-L.W., J.C., and C.C. performed parts of optimization studies and substrate screening experiments. F.-L.Z. conducted the DFT calculations and provided mechanism analysis. K.N.H. directed the DFT calculations and mechanism analysis. F.-L.Z., K.N.H., and Y.-F.W. co-wrote the manuscript. Competing interests: Authors declare no competing interests. Data and materials availability: Additional optimization, experimental procedures, characterization of new compounds, and all other data supporting the findings are available in the supplementary materials. Raw data underlying the NMR spectra are available in Zenodo (73).

\section{SUPPLEMENTARY MATERIALS}

science.sciencemag.org/cgi/content/full/science.abg0781/DC1

Materials and Methods

Supplementary Text

Figs. S1 to S26

Tables S1 to S7

Spectral Data

Calculation Data

References (74-99)

9 December 2020; accepted 9 February 2021

Published online 4 March 2021

10.1126/science.abg0781 


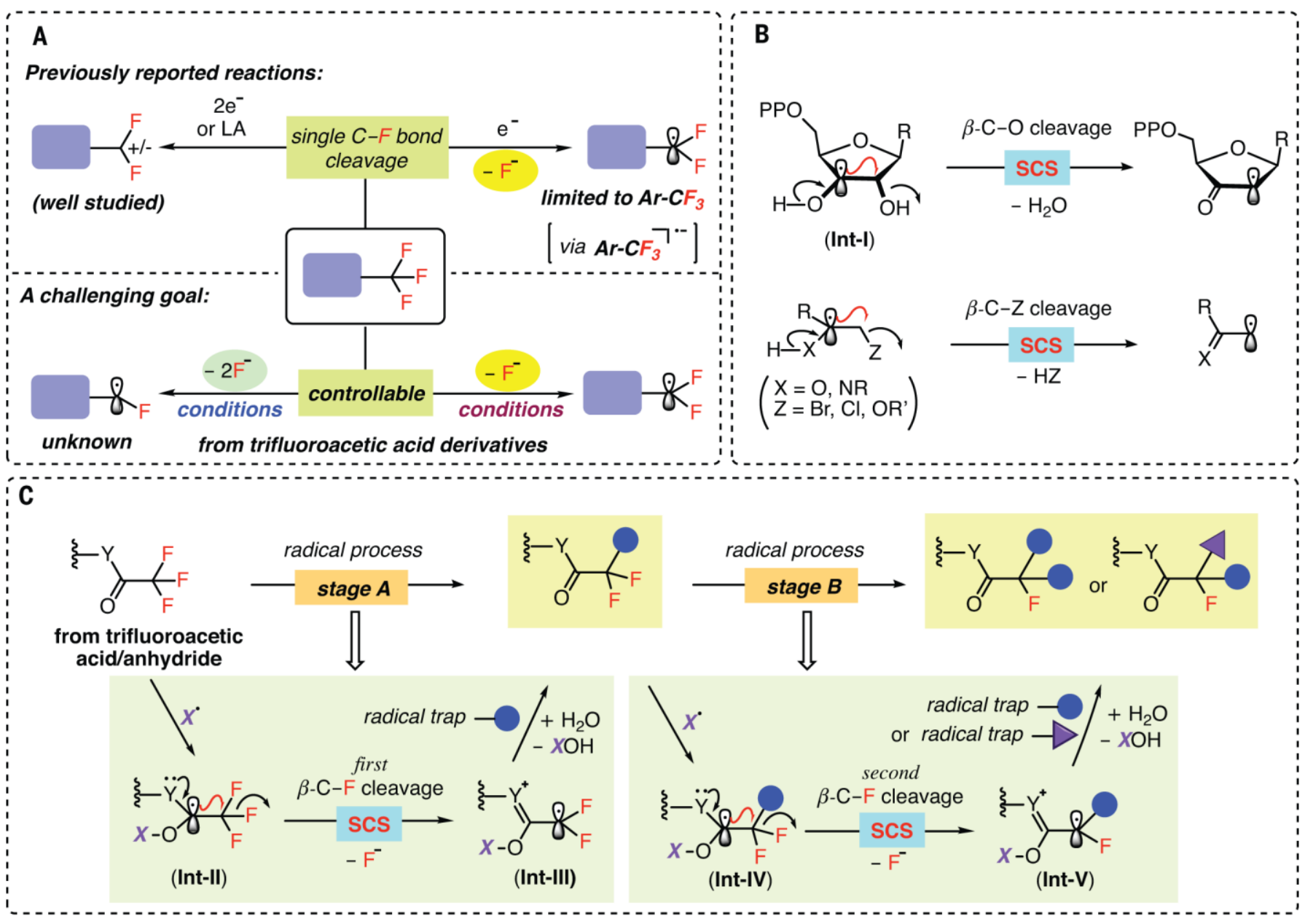

Fig. 1. Strategies for $\mathrm{C}-\mathrm{F}$ bond functionalizations of $\mathrm{CF}_{3}$ groups. (A) Defluorination of $\mathrm{CF}_{3}$ groups to difluorosubstituted intermediates (top) and the challenging goal of controllably generating di- and monofluoroalkyl radicals (bottom). (B) Spin-center shift (SCS) in biochemical conversions and organic synthesis. (C) This work: Two-stage process for sequential C-F bond cleavage via SCS. 


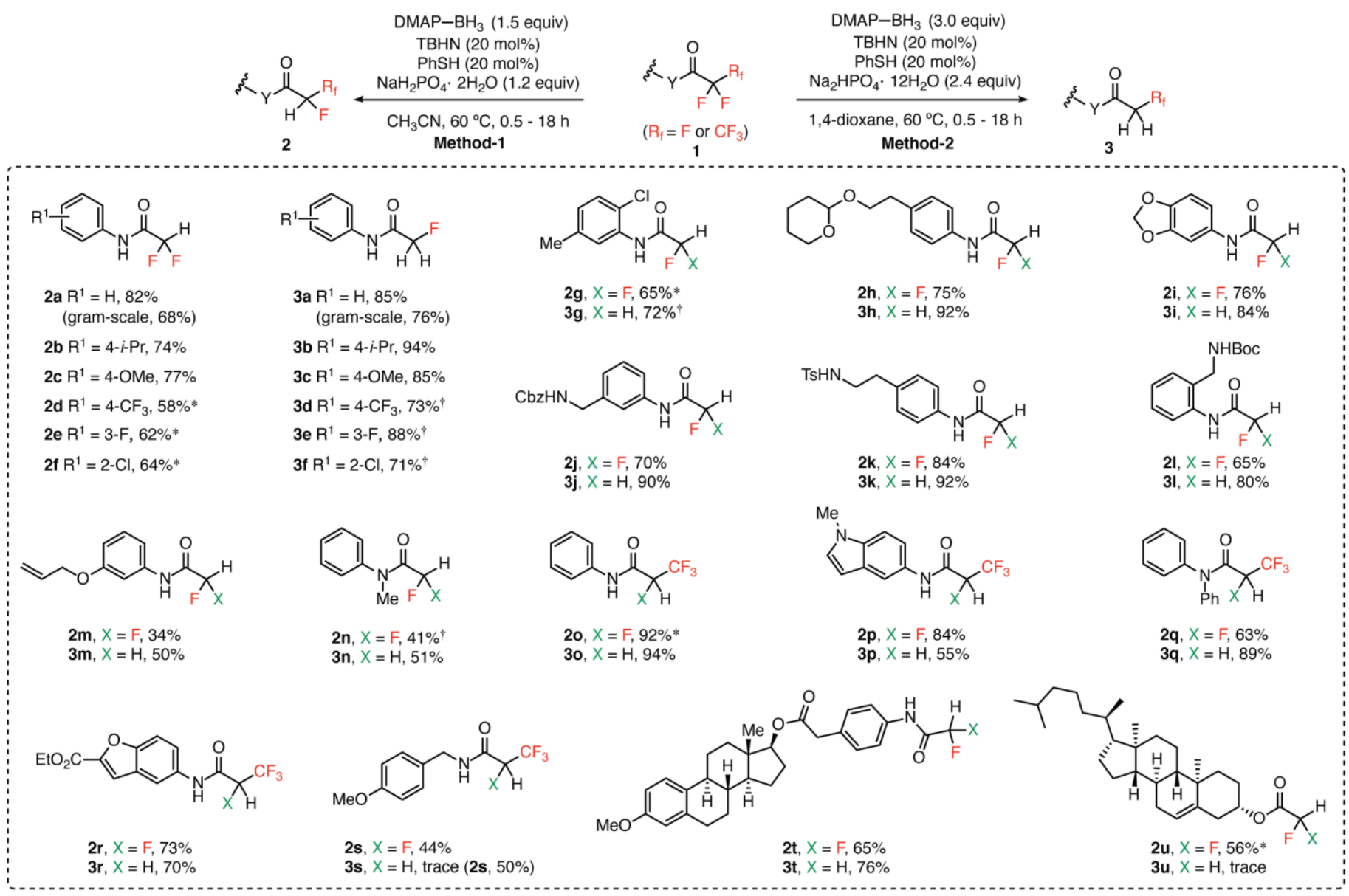

Fig. 2. Scope of mono- and dihydrodefluorination reactions. Method-1: 1 (0.3-0.5 mmol), DMAP-BH $\mathrm{DH}_{3}(1.5$ equiv), TBHN (20 mol\%), PhSH (20 mol\%), $\mathrm{NaH}_{2} \mathrm{PO}_{4} \cdot 2 \mathrm{H}_{2} \mathrm{O}$ (1.2 equiv) in $\mathrm{CH}_{3} \mathrm{CN}(0.1 \mathrm{M}), 60^{\circ} \mathrm{C}, 0.5-18$ hours, under nitrogen. Method-2: 1 (0.3-0.5 mmol), DMAP-BH 3 (3.0 equiv), TBHN (20 mol\%), PhSH (20 mol\%), $\mathrm{Na}_{2} \mathrm{HPO}_{4} \cdot 12 \mathrm{H}_{2} \mathrm{O}\left(2.4\right.$ equiv) in dioxane $(0.1 \mathrm{M}), 60^{\circ} \mathrm{C}, 0.5-18$ hours, under nitrogen. Isolated yields after chromatography are given. ${ }^{*} 1.2$ equiv of $\mathrm{DMAP}-\mathrm{BH}_{3}$ was used. $\dagger 2.0$ equiv of $\mathrm{DMAP}-\mathrm{BH}_{3}$ was used. 


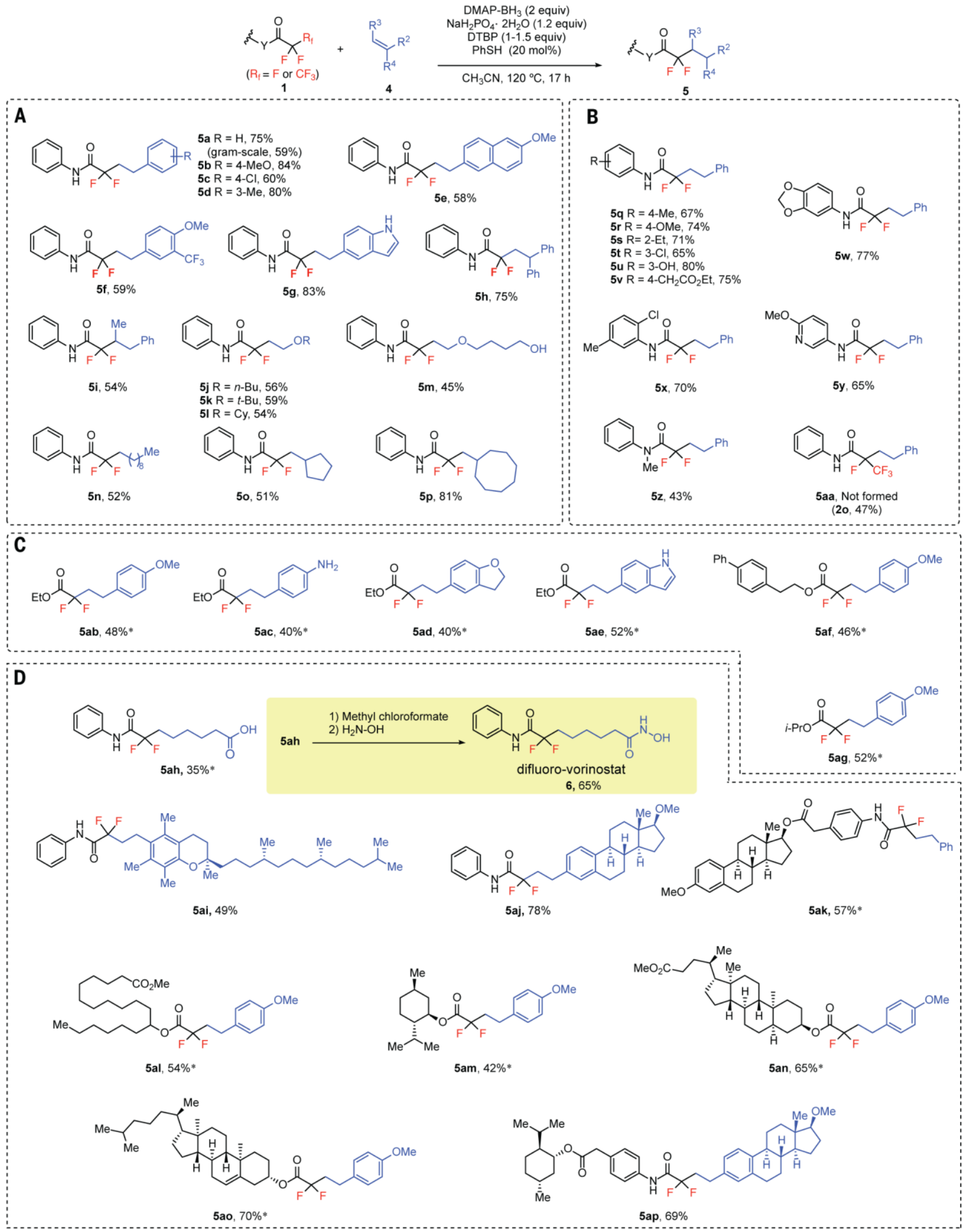

Fig. 3. Scope of defluorinative coupling reactions. Reaction conditions: substrate $1(0.2-0.3 \mathrm{mmol})$, alkene 4 (2-4 equiv), DMAP-BH 3 (2-3 equiv), DTBP (1-1.5 equiv), $\mathrm{PhSH}\left(2 \mathrm{O}\right.$ mol\%), $\mathrm{NaH}_{2} \mathrm{PO}_{4} \cdot 2 \mathrm{H}_{2} \mathrm{O}$ (1.2 equiv) in $\mathrm{CH}_{3} \mathrm{CN}$ $(0.1 \mathrm{M}), 120^{\circ} \mathrm{C}, 17$ hours, under nitrogen. Isolated yields after chromatography are given. (A) Scope of alkenes. (B) Scope of trifluoroacetamides. (C) Scope of coupling reactions between trifluoroacetates and alkenes. (D) Application to the synthesis of difluoroalkyl-substituted bioactive molecules. ${ }^{*}$ The reactions were carried out using alkene 4 ( $0.5 \mathrm{mmol}$ ), 1 (2 equiv), DTBP (1.5 equiv), $\mathrm{PhSH}\left(2 \mathrm{O}\right.$ ol\%), $\mathrm{NaH}_{2} \mathrm{PO}_{4} \cdot 2 \mathrm{H}_{2} \mathrm{O}$ (2 equiv) in $\mathrm{CH}_{3} \mathrm{CN}$ $(0.1 \mathrm{M}), 120^{\circ} \mathrm{C}, 12$ hours. 


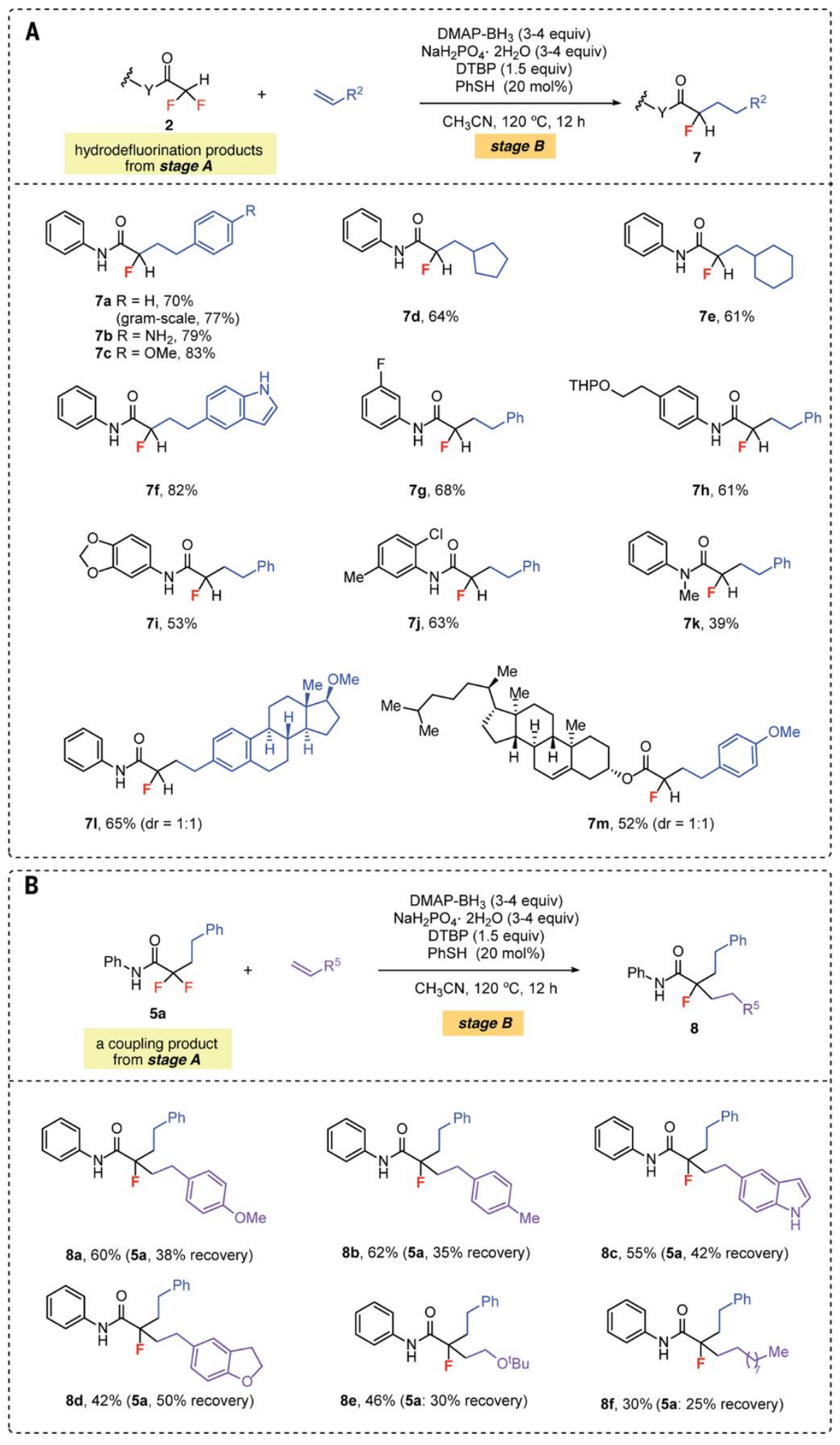

Fig. 4. Scope of various radical traps in two stages. Reaction conditions: compounds 2 or $5(0.2-0.3 \mathrm{mmol})$, alkene 4 (3-4 equiv), DMAP-BH 3 (3-4 equiv), DTBP (1.5 equiv), $\mathrm{PhSH}$ (20 mol\%), $\mathrm{NaH}_{2} \mathrm{PO}_{4} \cdot 2 \mathrm{H}_{2} \mathrm{O}$ (3-4 equiv) in $\mathrm{CH}_{3} \mathrm{CN}(0.1 \mathrm{M}), 120^{\circ} \mathrm{C}, 12$ hours, under nitrogen. Isolated yields after chromatography are given. (A) Scope of monohydrodefluorination/coupling sequence. (B) Scope of two successive defluorinative coupling reactions using different alkene partners. 

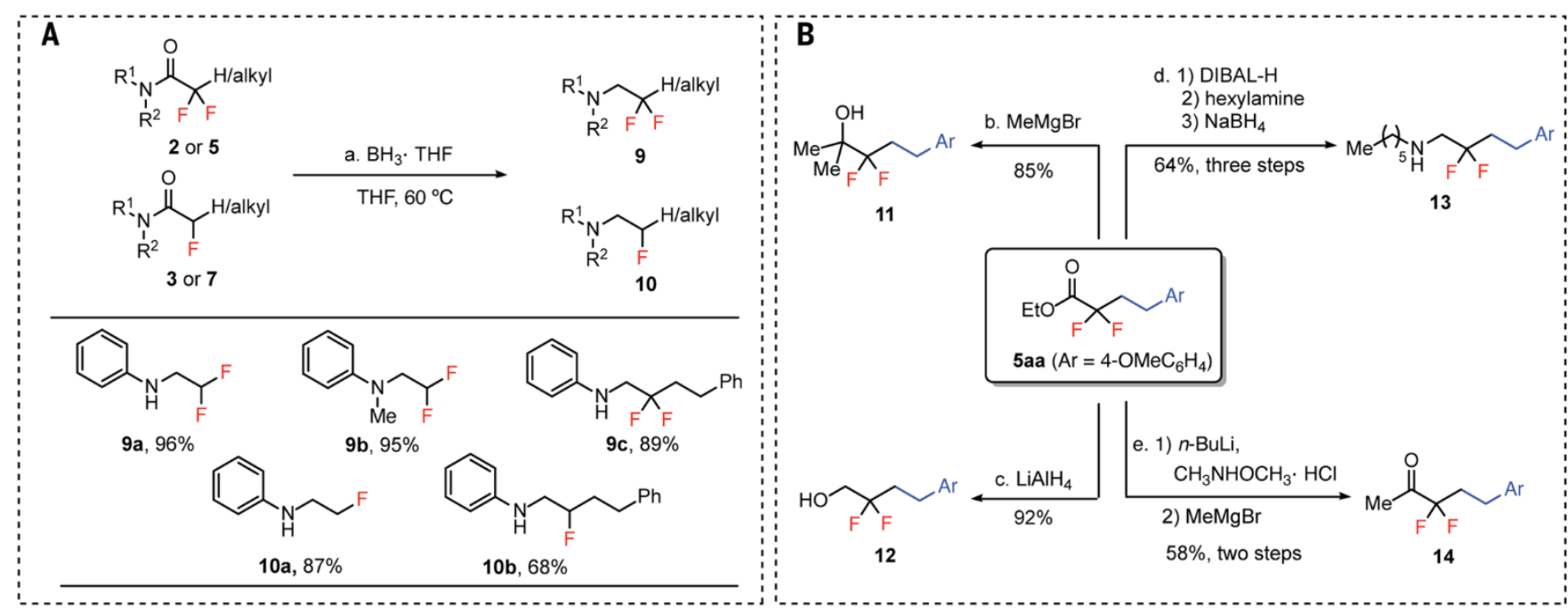

Fig. 5. Synthetic applications. (A) Reduction of di- and monofluoro amides for the synthesis of $\beta$-mono- and $\beta$-difluoroamines. (B) Transformations of difluoro acetate 5 aa to various difluoro products. Reaction conditions: (a) $\mathrm{BH}_{3}-\mathrm{THF}$ (2-3 equiv), THF, $60^{\circ} \mathrm{C}, 6-13$ hours; (b) $\mathrm{MeMgBr}$ (3.0 equiv), THF, $0^{\circ} \mathrm{C}$ to rt, 22 hours; (c) $\mathrm{LiAlH}_{4}$ (3.0 equiv), THF, $0^{\circ} \mathrm{C}$ to rt, 11 hours; (d) 1 ) DIBAL-H (1.0 equiv), $\mathrm{Et}_{2} \mathrm{O},-78^{\circ} \mathrm{C}, 5$ hours; 2 ) hexylamine (1.0 equiv), toluene, reflux, 4 hours; 3$) \mathrm{NaBH}_{4}$ (5.0 equiv), $\mathrm{MeOH}, 0^{\circ} \mathrm{C}$ to rt, 2 hours; (e) 1$) n$-BuLi (4.0 equiv), $\mathrm{N}, \mathrm{O}$-dimethylhydroxylamine hydrochloride (4.0 equiv), THF, $-78^{\circ} \mathrm{C}$ to rt, 13 hours; 2$) \mathrm{MeMgBr}$ (4.0 equiv), $\mathrm{THF}, \mathrm{O}^{\circ} \mathrm{C}$ to rt, 4 hours. 

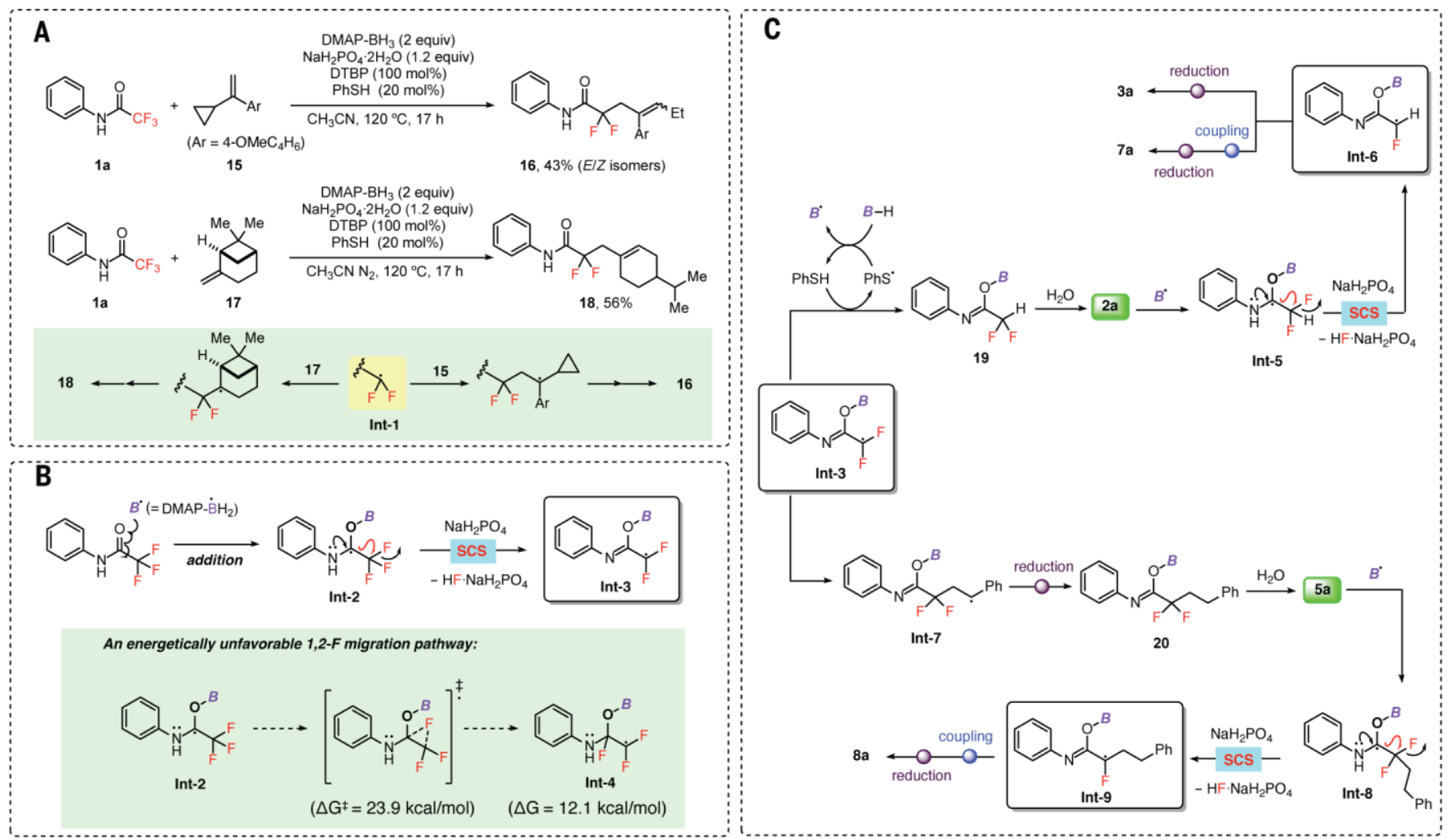

Fig. 6. Mechanistic studies and plausible mechanisms. (A) Radical clock experiments to verify the generation of the $\alpha, \alpha$-difluorocarbonyl radical intermediate. (B) Possible pathways for $C-F$ bond cleavage. (C) Proposed reaction pathways for the hydrodefluorination and defluorinative coupling reactions. 


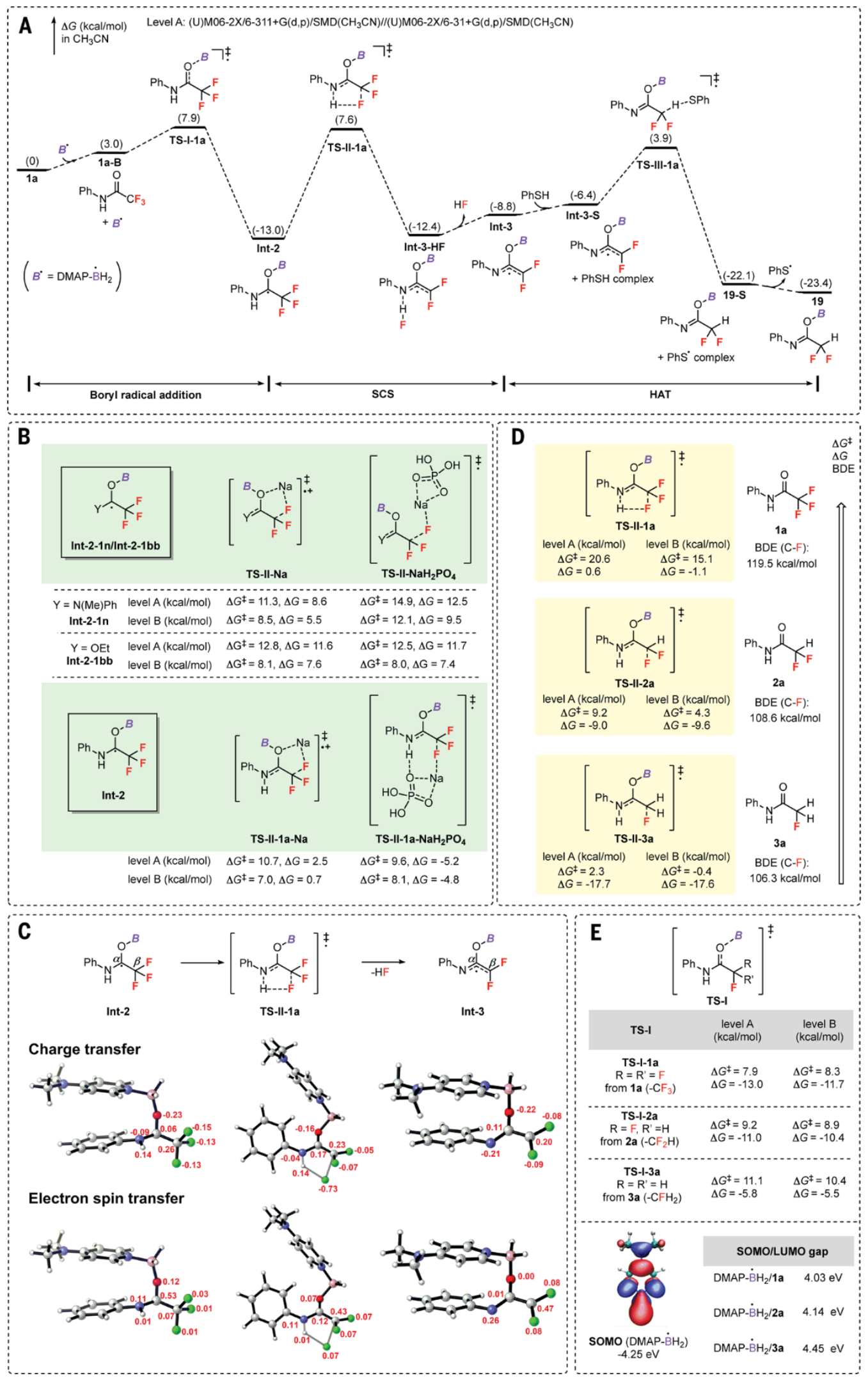

Fig. 7. Computational studies. Level A: (U)M06-2X/6-311+G(d,p)/SMD $\left(\mathrm{CH}_{3} \mathrm{CN}\right) / /(\mathrm{U}) \mathrm{M} 06-2 \mathrm{X} / 6-31+\mathrm{G}(\mathrm{d}, \mathrm{p}) /$

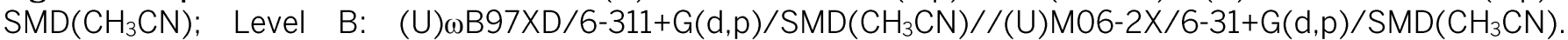
(A) Gibbs energy profile for the monohydrodefluorination of 1a; Free energies at level A are displayed. (B) SCS of intermediates (Int-2-1n, Int-2-1bb, and Int-2) assisted by Na+ or $\mathrm{NaH}_{2} \mathrm{PO}_{4}$. (C) Charge and electron spin transfer in the SCS of 1a; Hirshfeld charges and spin distributions were computed with Multiwfn 3.7, 3D structures were generated by CYLview (72). (D) Trend in the SCS processes of 1a, 2a and 3a, bond dissociation energies (BDE) were calculated at the CBS-4M level. (E) Trend in the addition of DMAP-BH${ }_{2} \bullet$ to the substrates, SOMO, LUMO energies were computed at the $(\mathrm{U}) \mathrm{M} 06-2 \mathrm{X} / 6-31+\mathrm{G}(\mathrm{d}, \mathrm{p}) / \mathrm{SMD}\left(\mathrm{CH}_{3} \mathrm{CN}\right)$ level, isovalue $=0.02$. 